Revue bibliographique pour le domaine irano-aryen

Volume 37-38-39 | 2018

Comptes rendus des publications de 2014-2016

\title{
Rika Gyselen. « Nœud d'Héraclès, nœuds lunaires et sceaux sassanides »
}

Julien Cuny

\section{(2) OpenEdition \\ 1 Journals}

\section{Édition électronique}

URL : http://journals.openedition.org/abstractairanica/46345

DOI : 10.4000/abstractairanica.46345

ISBN : 1961-960X

ISSN : 1961-960X

Éditeur :

CNRS (UMR 7528 Mondes iraniens et indiens), Éditions de l'IFRI

Référence électronique

Julien Cuny, «Rika Gyselen. " Nœud d'Héraclès, nœuds lunaires et sceaux sassanides » », Abstracta Iranica [En ligne], Volume 37-38-39 | 2018, document 45, mis en ligne le 30 décembre 2018, consulté le 02 octobre 2020. URL : http://journals.openedition.org/abstractairanica/46345 ; DOI : https://doi.org/ 10.4000/abstractairanica.46345

Ce document a été généré automatiquement le 2 octobre 2020.

Tous droits réservés 


\title{
Rika Gyselen. « Nœud d'Héraclès, nœuds lunaires et sceaux sassanides »
}

\author{
Julien Cuny
}

\section{RÉFÉRENCE}

Rika Gyselen. « Nœud d'Héraclès, nœuds lunaires et sceaux sassanides » in Céline Redard (éd.). Des Contrées Avestiques à Mahabad, via Bisotun. Etudes offertes en hommage à Pierre Lecoq. Neuchâtel : Recherches et publications, 2016, p. 233-257, (Civilisations du Proche-Orient. Série III. Religions et Culture vol. 2)

1 Etude iconographique consacrée à un motif attesté sur 20 sceaux sassanides représentant un «nœud plat ", dont la réapparition dans le vocabulaire sassanide peut être le fruit d'une résurgence d'un motif iranien attesté au I ${ }^{\mathrm{er}}$ millénaire av.n.è. ou un emprunt au répertoire gréco-romain $\mathrm{du}$ «nœud d'Héraklès». Cependant, un traitement particulier et l'ajout fréquent d'éléments animaliers ou végétaux singularisent nettement la production sassanide. L'A. passe en revue ses significations possibles, peut-être astrales, tout en rappelant que l'ancienneté et l'origine babylonienne du motif des nœuds lunaires, proche mais distinct, et jadis proposée par J. Duchesne-Guillemin, n'est pas démontrée. 


\section{AUTEURS}

\section{JULIEN CUNY}

Conservateur au Musée du Louvre, Paris 